\section{IRRITABLE BOWEL SYNDROME AND PSYCHOLOGICAL STRESS}

\author{
Barbara S Bayne, MA (RAU)
}

Anita D Stuart, D.Litt.et Phil.

Professor, Department of Psychology

Rand Afrikaans University

H Gertie Pretorius, D.Litt.et Phil. Professor, Department of Psychology

Rand Afrikaans University

\section{ABSTRACT}

The purpose of this study was twofold. The first aim was to clarify the relationship between psychological stress and Irritable Bowel Syndrome (IBS) by establishing whether individuals suffering from IBS experience minor stress differently from healthy individuals in terms of its frequency or intensity. The second aim was more general and concerns theory building in a field filled with ambiguity and confusion. Two groups, one comprising IBS sufferers and the other healthy controls, completed the Daily Stress Inventory and the Occupational Stress Inventory questionnaires designed to measure minor daily and occupational stress respectively. The findings indicate that IBS sufferers do not experience more stress than healthy individuals, but they experience the stressors with greater intensity.

\section{ABSTRAK}

Die doel van die studie was tweeledig. Eerstens is daar gepoog om duidelikheid te kry oor die verband tussen sielkundige stres en Prikkelbare Dermsindroom (PDS), deur te bepaal of individue wat aan PDS ly geringe stres anders ervaar as gesonde individue in terme van gereeldheid of intensiteit. Die tweede doelwit was meer algemeen en spreek die kwessie van teorie ontwikkeling aan in 'n veld gevul met dubbelsinningheid en verwarring. Twee groepe, een bestaande uit PDS lyers en die ander ' $n$ gesonde kontrolegroep, het die "Daily Stress Inventory" en die "Occupational Stress Inventory" voltooi. Die vraelyste is ontwerp om onderskeidelik daaglikse stres en werkstres te meet. Die resultate dui daarop dat PDS lyers nie meer stres ervaar as die gesonde individue nie, maar dat hulle wel die stressors ervaar met groter intensiteit.

\section{INTRODUCTION}

Irritable Bowel Syndrome (IBS) is a common bowel disorder characterised by abdominal pain, gaseousness and an altered bowel habit, each of which is present to a variable degree, and is found in the absence of any recognised gastrointestinal pathology (Bennet, 1989:51). It is estimated to affect $8-15 \%$ of the population, and accounts for between $50 \%$ and $70 \%$ of referrals to gastroenterologists (Drossman, Sandler, McKee \& Lovitz, 1982:326).
There is no consensus amongst clinicians and researchers concerning the underlying cause of this syndrome. Organic causes which have been suggested include abnormal motor activity of the intestinal tract (Snape, Carlson \& Cohen, 1976:125), abnormal gut hormone, secretion and sensitivity (Ritchie, 1973:125-132), and diet (Schuster, 1983). However, many studies have indicated that psychological factors are important and that patients with this syndrome are more neurotic, depressed or anxious than others (Hislop, 1971:455; Young, Alpers, Norl \& Woodruff, 1976:162). A common thread throughout both organic and psychological investigations is the role. that stress plays in this disorder, particularly in its onset or in the exacerbation of IBS symptoms.

For example, Drossman et al. (1982:326-330) found that $70 \%$ of a general population sample reported that stressful events, such as marital difficulties or financial worries, caused them constipation or diarrhoea, and $54 \%$ reported the caused abdominal pain or discomfort. IBS sufferers within this population were even more likely to report these effects of stress.

A number of pathways by which stress results in these symptoms have been suggested. Whitehead, Engel and Schuster (1980:404-413) suggest that some people have a biological hyperactivity of the colon; stress and emotional arousal as well as dietary factors may cause this response. More radically, Latimer (981:475) suggests that the symptoms of both IBS and anxiety result from a general physiological over-reactivity to stress. While a number of studies have investigated the link between major life event stressors and health, no studies are to be found in which normal, healthy individuals are compared to IBS patients with regard to daily life stressors. This is somewhat incongruous in light of the fact that recent stress research has emphasised the impact of everyday hassles or mundane irritants and stressors on health, suggesting that chronic, low level stressors may have a far greater impact on mental and physical well being than a single acute exposure to a major stressor.

Thus far, studies conducted into the relationship between daily stressors and IBS have investigated the effect that these stressors have on symptom severity, specifically focusing on symptom fluctuations preceding or following exposure to daily stress. For example, Suls, Wan and Blanchard (1994:103) tested the hypothesis that daily sources of stress increase symptoms in IBS patients. They found, however, that prior and concurrent daily stress had no consistent effects in increasing gastrointestinal symptoms. In a later study by Dancey, Whitehouse, Painter and Backhouse (1995:827), an increase in symptom severity was found to precede an increase in the severity of commonplace stressors.

\section{CURRENT RESEARCH}

The dearth of studies into the relationship between minor stress and IBS is striking, particularly in the light of the 
prevalence of this disorder and the frequency with which stress is associated with it. Furthermore, the available studies and results have tended to be highly erratic and variable, providing little clarity but rather prompting an ever-increasing awareness of the complexity of the factors involved in IBS.

The purpose of this study was twofold. The first aim was to clarify the relationship between psychological stress and Irritable Bowel Syndrome (IBS) by establishing whether individuals suffering from IBS experience minor stress differently from healthy individuals in terms of its frequency or intensity. The second aim was more general and concerns theory building in a field filled with ambiguity and confusion.

The specific objective of the present study was thus to clarify the relationship between minor stress and IBS by ascertaining whether there are statistically significant differences between a group of female patients $(n=52)$ diagnosed with IBS, and a group of females $(n=52)$ with no gastrointestinal problems, regarding their scores on two measures of stress.

\section{METHOD}

\section{Sample selection}

Patients suffering from IBS were recruited via several articles in newspapers and a women's magazine appealing for volunteers. One consequence of this method of sampling (using individuals who read an article and volunteered themselves as research subjects to a study on IBS) is an experimental group that is not altogether random in its makeup. The respondents were almost exclusively white females and it was therefore decided to control for gender and race by only using white females in the study.

For inclusion in the study the following criteria were met: Women between the ages of 20 and 70 years, with a diagnosis of IBS confirmed by a medical practitioner.

A control group of IBS non-patients was then selected, consisting of women between the ages of 20 and 70 who had never been diagnosed as having IBS. Each group consisted of 52 subjects.

\section{Measuring instruments}

Following a structured interview in which biographical data and a medical history were obtained, both groups completed two psychometric questionnaires designed to measure minor daily and occupational stress, namely the Daily Stress Inventory (DSI) and the Occupational Stress inventory (OSI) respectively.

Stress, as defined and measured by the DSI, is the subjectively perceived, cumulative impact of relatively minor, daily, 'annoying' events (Brantley \& Jones, 1989:1). Both the frequency with which an event occurs, and its relative impact represent important dimensions in an individual's stress experience. Events may vary along these two dimensions from a low to high impact. The frequency and the impact of stressful events interact with one another resulting in a measurable experience of stress for a given time period along these two dimensions.

The items in the DSI are grouped into five content clusters, namely: Interpersonal Problems, Personal Competency, Cognitive Stressors, Environmental Hassles and Varied Stressors. For each cluster, the respondent records the frequency with which particular stressors occur, as well as the impact that they have for the individual concerned, that is, their perceived stressfulness. Each participant in the study completed the DSI, recording the frequency and impact of various minor stressors experienced in a 24-hour period.

The data from 433 adult subjects were used to calculate internal consistency reliability (Brantley \& Jones, 1989:14). Alpha co-efficients of .83 and .87 were reported. In terms of validity, studies show correlation with the Hassles and Uplifts Scale $(.33-.57)$ and other measures of stress (Brantley \& Jones, 1989:14-16).

The second questionnaire, which was completed by the IBS and non-IBS groups, was The Occupational Stress Inventory (OSI). This questionnaire was developed to provide a generic measure of various occupational stressors that would apply across different occupational levels and environments. The OSI provides a concise measure of three dimensions or domains of occupational adjustment, namely occupational stress, psychological strain and coping resources. A number of sub-scales provide detailed information on each of these dimensions by measuring specific attributes of the environment or the individual that represent important facets of the domains.

The three questionnaires within the OSI may be administered separately or together, and include the following: The Occupational Roles Questionnaire (which analyses stress due to occupational roles), The Personal Strain Questionnaire (which measures psychological strain reflected in behaviours and attitudes) and The Personal Resources Questionnaire (which analyses effective coping through the use of personal resources).

An internal consistency analysis of the OSI was completed by a sample of 549 adults. Alpha co-efficients of .89 to .99 were reported for the total questionnaire scores while the co-efficients for individual scales ranged from .71 to .94 (Osipow \& Spokane, 1987).

\section{Hypotheses}

Two composite hypotheses have been formulated to establish whether differences between the IBS group and the non-IBS group exist in terms of two stress measures. These are:

\section{Hypothesis 1}

There is a statistically significant difference in the vectors of averages between Group 1 (IBS group) and Group 2 (non-IBS group) regarding the Daily Stress Inventory's sub-scales taken together. 


\section{Hypothesis 2}

There is a statistically significant difference in the vectors of averages between Group 1 (IBS group) and Group 2 (non-IBS group) regarding the Occupational Stress Inventory's sub-scales taken together, the sub-scales of the Personal Strain Questionnaire and the sub-scales of the Personal Resources Questionnaire.

\section{Statistical Techniques}

Once the tests have been completed by both groups they were hand scored, and a statistical analysis performed to establish whether significant differences existed between the two groups. Three statistical techniques were employed in the analysis of the data, namely Hotelling's T2-Test, Student's t-test and the F-test. Hotelling's T2-Test was utilised to establish whether the vectors of averages between the two groups (IBS group versus non-IBS control group) differed statistically from one another with regard to the scores of the Daily Stress Inventory. The significance of F-values was determined by the F-tables, where the ruling criterion was set at 0,05 . Differences in this range were considered significant, where Hotelling's T2 was shown to be statistically significant. In this case, Student's T-Test was used to ascertain in which variables the differences manifested.

\section{RESULTS}

Results were obtained on 104 subjects (52 IBS patients, 52 healthy controls). Each group consisted of white women between the ages of 20 and 70 years (Table 1). There were no group differences with regard to sex and race, but a statistically significant difference in age was controlled for in the analysis by creating two age divisions within each group: a younger group (20-39 years) and an older group (aged 40-70).

\section{Differences in daily stress between the IBS group and the healthy controls}

The results of the present study indicate that the averages of the IBS and control group are not statistically significant in terms of the frequency of stressful events reported. In other words, the IBS group did not report significantly more or less stressful events to have occurred in the previous 24 hours than the non-IBS group. Significant differences were noted, however, in the intensity with which these events were experienced. Thus the Impact scores for the sub-scales of Interpersonal $(p=0,039)$, Environmental Hassles $(p=0,006)$ and Varied Stressors $(p=0,003)$, as measured by the DSI were elevated for the IBS group, showing that the stressors in these scales created greater stress for the IBS sufferers.

\section{Differences in occupational stress between the IBS group and the healthy controls}

A statistical analysis of the scores of the

Occupational Stress Inventory showed a division in the IBS group by age. Younger IBS suffereis (ages $20-39$ ) did
TABLE 1: Description of The IBS Group and the Control Group.

\begin{tabular}{|c|c|c|}
\hline Demographic features & $\begin{array}{c}\text { IBS group } \\
n=52\end{array}$ & $\begin{array}{c}\text { Control group } \\
n=52\end{array}$ \\
\hline \multicolumn{3}{|l|}{ AGES } \\
\hline $20-29$ & 10 & 11 \\
\hline $30-39$ & 20 & 13 \\
\hline $40-49$ & 14 & 6 \\
\hline $50-59$ & 7 & 14 \\
\hline $60-69$ & 1 & 8 \\
\hline EDUCATIONAL LEVEL & & \\
\hline$<$ Matric & 11 & 3 \\
\hline Matric & 15 & 24 \\
\hline Post Matric & 26 & 25 \\
\hline \multicolumn{3}{|l|}{ OCCUPATION } \\
\hline None & 1 & 7 \\
\hline Technical & 2 & 2 \\
\hline Business & 21 & 16 \\
\hline Professional & 5 & 20 \\
\hline Service & 11 & 6 \\
\hline Manufacturing & 2 & 1 \\
\hline \multicolumn{3}{|l|}{ EMPLOYMENT STATUS } \\
\hline \multicolumn{3}{|l|}{ Homemaker/ } \\
\hline \multicolumn{3}{|l|}{ unemployed/ } \\
\hline retrenched & 9 & 9 \\
\hline Part-time employment & 9 & 12 \\
\hline Full-time employment & 34 & 31 \\
\hline \multicolumn{3}{|l|}{ MONTHLY INCOME } \\
\hline Ro - R2 000 & 11 & 7 \\
\hline$R 2000-R 6000$ & 31 & 28 \\
\hline$>\mathrm{R} 6000$ & 10 & 17 \\
\hline \multicolumn{3}{|l|}{ NUMBER OF CHILDREN } \\
\hline 0 & 14 & 1 \\
\hline $1-3$ & 34 & 39 \\
\hline $4+$ & 4 & 2 \\
\hline
\end{tabular}


not differ significantly from the healthy controls on any of the sub-scales. In contrast, the older IBS group (aged 40 - 70) and the overall IBS group showed significantly higher occupational stress levels than the non-IBS group on five dimensions: Psychological Strain $(p=0,000)$, Interpersonal Strain $(p=0,003)$, Physical Strain ( $p=$ $0,014)$, Recreation $(p=0,025)$ and Social Support $(p=$ 0,036 ). A discussion of the results follows.

\section{DISCUSSION}

The results of this study show that for both daily and occupational stress, group differences between the IBS and non-IBS groups are apparent. In particular, the present study has revealed age as a significant factor in determining the effect that stress has on IBS sufferers. These differences will now be discussed in greater depth.

\section{Daily stress}

While the impact of major life stress on health has been widely researched (Holahan \& Moos, 1985:739; Holmes \& Rahe, 1967:213), a more recent trend in stress research is towards measuring the impact of everyday hassles or mundane irritants and stressors on health. Earlier studies have attempted to compare frequency and severity of stressful life events in persons with and without IBS (Fava \& Pavan, 1976/77:93; Mendeloff, Monk, Siegel \& Lilienfield, 1970:14-17) and showed that patients with IBS recall more stressful events than asymptomatic control subjects or patients with inflammatory bowel disease. A more recent study by Dinan, O'Keane, O'Boyle, Chua and Keeling (1991:26-28) found that IBS patients reported more life events that were perceived as negative, when compared with patients with a peptic ulcer. These findings, however, contradicted a prior study by Drossman, McKee, Sandler, Mitchell, Cramer, Lowman and Burger (1988:701708 ) in which patients with IBS reported significantly fewer stressful life events, and their life events were significantly less stressful than those of asymptomatic control subjects.

The results of the present study indicate that the IBS group did not report significantly more or less stressful events to have occurred in the previous 24 hours than the non-IBS group. Significant differences between the two groups were noted, however, in the intensity with which the IBS group experienced these events. In particular, the IBS group showed elevated stress on the sub-scales measuring Interpersonal Problems, Environmental Hassles and Varied Stressors, as measured by the Daily Stress Inventory.

\section{Interpersonal problems}

The elevated scores for the Interpersonal Problems subscale indicate that the IBS group tends to experience greater levels of stress when dealing with minor interpersonal difficulties, for example being interrupted while talking, being ignored by others or arguing with someone. In many of the studies that have investigated the relationship between IBS and stress, a number of different stressors involved in the precipitation, exacerbation or maintenance of IBS symptoms have been identified which relate specifically to interpersonal difficulties. In an early study by Chaudhary and Truelove (1962:307-322), the most frequently reported stressful life events for female IBS sufferers included difficulties in marriage, problematic family relationships and concerns about their children. Clearly, difficulties in interpersonal relationships are experienced as being particularly stressful for individuals with IBS, and in addition, seem to play a role in the onset, exacerbation or maintenance of gastrointestinal symptoms.

Internal coping resources are hypothesised to affect the ability and effort of individuals to recognise a potentially stressful event and trigger a response reaction to the stimulus in an attempt to prevent or eliminate potential distress (Lin \& Ensel, 1989:382-399). When interacting with others, personality factors may act as a personal resource that will mediate the stress created by interpersonal problems.

Of particular importance is the personality disposition underlying a sense of self-efficacy. According to Bandura (1982:122) perceived self-efficacy involves a judgement of how effectively one can execute courses of action which are necessary to deal with situations involving unpredictable and stressful elements. In the case of interpersonal problems, this may include skills such as conflict management, assertiveness and a sense of self-confidence. Previous research, however, suggests that in terms of personality characteristics, IBS patients tend to be compulsive, over conscientious, dependent, sensitive, guilty and unassertive (Langeluddecke, 1985:218). Clearly, an individual with these personality characteristics is unlikely to have well-developed internal coping resources based on a sense of self-efficacy.

in conclusion, previous research has identified interpersonal difficulties as important stressors that influence the onset and/or exacerbation of IBS symptoms. The present research supports these findings, indicating that the IBS group as a whole tends to experience Interpersonal Problems as more stressful than their healthy counterparts. Personality characteristics commonly found in IBS patients that seem to be incompatible with Bandura's concept of self-efficacy may reduce the individual's ability to cope with interpersonal stressors in an effective manner.

\section{Environmental hassles}

Previous research conducted to investigate specific types of stressors associated with the onset or exacerbation of IBS symptoms has typically shown two areas to be of primary importance: problematic interpersonal relationships and contextual frustrations and irritations (Arun, Kanwal, Vyas \& Sushil, 1993:108-112; Mendeloff et al. 1970:1417). This was confirmed in the present study, as indicated by elevated scores for the IBS group in the Interpersonal Problems sub-scale and the Environmental Hassles subscale. 
The Environmental Hassles sub-scale of the DSI measures the frequency and intensity of everyday minor stressors that are encountered regularly during contact with the outside world. When grouped by age, IBS sufferers did not differ from the non-IBS group in terms of Environmental Hassles. This would indicate that the two groups of women (IBS and non-IBS) tended to experience similar frequencies of situational stressors, and did not differ in terms of the perceived intensity of these stressors.

As a group, however, the IBS sufferers showed statistically significant differences in their stress levels for this subscale. When considering the entire group, the women with IBS reported experiencing a similar number of environmental hassles to the controls, yet perceived them to be more stressful.

The types of environmental stressors measured by the DSI represent instances where the individual is unable to control the stimulus creating the stress. As such, in each instance the individual has experienced a loss of control over his or her environment, which is then perceived to elevate stress. Gardner, Ostrowski, Pino, Morrell and Kochevar (1992:589) have suggested that perceived control, the belief that one is able to exert control over a noxious event, is a powerful mediator of an individual's response to stressful situations. Several reports indicate that aversive events do not have the same impact upon persons who differ in their beliefs about the controllability of laboratory procedures. Specifically, aversive stimuli do not have the same degree of debilitating effect when subjects believe that they can control the onset or offset of those events. Thus, the lack of perceived control when exposed to environmental hassles might adversely affect the IBS patient's ability to cope with everyday stressors encountered within the environment.

Another concept closely related to the individual's attitude towards the environment and locus of control is a constellation of related personality characteristics that is termed 'hardiness' by Kobasa, Maddi and Kahn (1982:168). Included in this concept are the following elements: commitment to oneself, an attitude of vigorousness towards the environment, a sense of purpose, and an internal locus of control. According to Kobasa and her colleagues, hardiness can be viewed as a personal resource that is able to influence an individual's reaction to life events or stressors, and may buffer or reduce the impact of a stressor on subsequent illness (Smith, 1985:537-579). It is possible that the IBS group in the present study lacks these qualities of hardiness, which may negatively affect their ability to cope effectively with environmental hassles.

\section{Varied stressors}

The Varied Stressors sub-scale of the DSI includes minor stressors of a personal nature, as well as contextual stressors, for example: being criticised, forgetting something, minor altercations and concerns over physical appear- ance. In this sub-scale the IBS group scored significantly higher than the healthy control group in terms of their experience of the intensity of the stressors. Again, when grouped according to age, there was no difference between the IBS group and the healthy controls in terms of either the frequency or intensity of varied stressors they experienced. Once again, the characteristics of hardiness, self-efficacy and perceived control discussed above may buffer the personal and contextual stressors described in this sub-scale, however, for the IBS group a lack of personal coping resources, including assertiveness and conflict management, may increase the perceived stressfulness of the Varied Stressors.

\section{Occupational stress}

The results of the Occupational Stress Inventory (OSI) showed a division in the IBS group by age. The OSI also provides a measure of minor stress, but the emphasis is on minor stressors that are typically experienced within an occupational environment. The younger IBS sufferers (ages $20-39$ ) did not differ significantly from the healthy controls on any of the sub-scales. In contrast, the older IBS group (aged $40-70$ ) and the overall IBS group showed significantly higher occupational stress levels than the non-lBS group on five dimensions: Psychological Strain, Interpersonal Strain, Physical Strain, Recreation and Social Support. Each of these will now be discussed.

\section{Psychological strain}

The Psychological Strain sub-scale of the OSI measures the extent of psychological strain and/or emotional problems, which are currently being experienced by the individual. The elevated score in this domain indicated that the IBS group experiences more emotional problems than the healthy controls, and these psychological difficulties are a source of stress for the IBS group. That individuals suffering from IBS are psychologically impaired or disturbed in some way is a widely held belief, and consequently numerous studies have been conducted to evaluate this component of IBS (Blanchard, Schwarz \& Radnitz 1987:348).

Research indicates that psychological abnormalities are frequently encountered in IBS patients, being diagnosed in $50 \%$ to $60 \%$ of clinic patients (Whitehead, Bosmajian, Zonderman, Costa \& Schuster, 1988:709), but the relationship between psychopathology and IBS is still not clear. It is unclear. whether symptoms of psychological distress are causally related to IBS or whether they are a consequence of this disorder. Studies by Whitehead et al. (1988:709) and Drossman et al. (1988:701) indicate that that the psychological symptoms are not causally related to IBS but rather that they are related to health care seeking behaviour in patients with IBS. IBS patients, in contrast to IBS non-patients (individuals who meet the criteria for IBS but who do not consult physicians for the disorder) and healthy controls, have a higher proportion of abnormal personality patterns and greater illness behaviour (Fava \& Pavan, 1976/77:93-99). Psychological factors interact with 
physiological disturbances and may determine how the abdominal illness is experienced.

Patients with IBS often believe or fear that they have cancer or some other life threatening illness which may also contribute to psychological distress (Walker, Roy-Byrne, Katon, Li, Amos \& Jiranek, 1990:1656-1661). In addition; the onset of IBS may be fairly rapid, and uncertainty about its causes and the lack of a definite diagnosis may all contribute to psychological unease. As such, physicians have a role to play in educating and reassuring IBS patients to alleviate the stress that may result from recurrent, persistent or intensified gastrointestinal symptoms.

\section{Interpersonal strain}

The Interpersonal Strain sub-scale of the OSI measures the extent of disruption in interpersonal relationships, as is essentially the same as the Interpersonal Problems subscale of the DSI described above. The elevated scores on both scales for the IBS group demonstrate inadequate interpersonal skills, which affect individuals with IBS on a daily basis in their home and/or work environment.

IBS samples, in general, tend to be slightly more introverted than either general medical patients are or healthy control groups (Esler \& Goulston, 1973:16-18; Latimer, 1981:475-483). Therefore, in addition to the interpersonal difficulties described above under Interpersonal Problems, introverted IBS patients may experience additional stress at work when confronted with minor interpersonal stresses.

\section{Physical strain}

According to the results of the present study, significant differences exist between the physical strain of the IBS group and the control group. Elevated scores are found for the IBS group as a whole, and again in the older group of IBS sufferers. The Physical Strain sub-scale of the OS] measures complaints about physical illness or self-care habits.

These results are not altogether unexpected, since the sampling method used would have resulted in a selfselected sample of health care seekers. IBS patients who regularly engage in health care seeking behaviours typically consult general practitioners and specialists regularly and elevated scores for this sub-scale could simply be a reflection of their health concerns.

Community studies have shown that only a minority of persons who experience IBS-type symptoms seek medical attention for them (Drossman et al. 1982:326; Sandler, Drossman, Nathan \& McKee, 1984:314). It has been suggested that people with IBS symptoms become patients for two main reasons: those related to their symptoms (such as exacerbation of the complaints, fear about serious illness, pending disability, or the use of self-prescribed drugs) (Drossman et al. 1988:701-708) and those related to psychosocial factors (such as psychological stress, stressful life events, psychosocial disturbances and poor social support). Therefore, the decision to seek medical advice for IBS-type symptoms is dependent not only on the severity of the gastrointestinal symptomatology, but also upon a variety of psychological and socio-cultural factors (Whitehead, Winget, Fedoravicius, Wooley \& Blackwell, 1982:202-2-7).

Research has shown that women with IBS symptoms are more likely to engage in health care seeking behaviour than men (Langeluddecke, 1985:218-226), with at least twice as many females as males consulting their doctors with this problem (Latimer, 1981:475-476). It is also of interest that persons experiencing psychological distress are more likely to seek care for comparable symptoms than those without (Langeluddecke, 1985:475-483). The high scores for the Psychological Strain sub-scale of the OSl indicate that the sample in the present study was experiencing emotional distress, which may have compounded their concerns about their health.

To this point, the discussion has focused on the sub-scales of the DSI and the OSI in which the IBS group has shown elevated stress levels compared to the healthy control group. The following two sections concern potential mediators of stress, namely Recreation and Social Support, yet the results indicate that the IBS group make less use of these two mechanisms to reduce their stress.

\section{Recreation}

Recreational activities have long been considered an effective mediator of stress (Kaplan, Sallis \& Patterson, 1993), and the Recreational sub-scale of the OSI measures the extent to which the individual makes use of, and derives pleasure and relaxation from regular recreational activities. The results showed that the older IBS group (aged $40-70$ ) and the overall IBS group engage in significantly less recreational activities than the corresponding non-IBS group. One reason that IBS patients may not engage in recreational activities to the same extent as individuals without IBS is the debilitating effect that the physical symptoms of IBS may have. Gassiness, constipation or diarrhoea may make IBS sufferers reluctant to move beyond their home environment to an unfamiliar place where they may have to get to a bathroom quickly (Dancey \& Backhouse, 1993:1443-1448).

\section{Social support}

The second mediating variable in the OSI that is significant, is that of Social Support. The Social Support subscale of the OSI measures the extent to which the individual feels support and help from those around him/her. As with the Recreation sub-scale described above, individuals in the IBS group used social support significantly less than the healthy controls, failing to exploit the buffering effect that social support potentially has. In times of psychological need, social support can provide emotional sustenance, informational guidance and tangible assistance. Empirical evidence from a variety of sources has demon- 
strated an inverse relationship between social support and various indices of physical and mental illness (Holahan \& Moos, 1985:739-747; Kobasa, 1979:1; Lin \& Ensel, 1989:382). Caplan (1974) has described three stressmediating functions provided by social support systems. Firstly, social support systems help people to organise their skills and resources for coping with the stressful life event; secondly, they share the burden of the stress; and finally, social resources may provide emotional and instrumental support. Thus, in times of psychological need social support can provide emotional sustenance, informational guidance, tangible assistance, as well as opportunities for social comparison and self-esteem, all of which can be secured through membership in a group in which one feels a sense of belonging (Krantz, Grunberg \& Baum, 1985:349-383).

In the case of irritable bowel syndrome, patients do not typically discuss their symptoms (Dancey \& Backhouse, 1993:1443-1448). This may be in part due to the socially inappropriate nature of IBS symptoms - society does not sanction public discussion of bowel movements or flatulence. Even if this were not the case, however, many individuals with IBS feel a sense of shame resulting from the lack of control they have over their bodies, and as such keep silent about their discomfort. The result is that IBS patients may feel isolated from other 'normal' people, unable to communicate their discomfort and consequently separated from the buffering effect of social support. This factor, combined with the increased stress of the IBS group may mean that any discussion of their symptoms is stressful in itself and is avoided. Thus the benefits of social support described above remain elusive.

In conclusion then, empirical evidence from a variety of sources has demonstrated the powerful buffering effect that social support may have on stress. The present study indicates that the IBS group does not use this resource effectively, and a number of possible reasons for this were presented.

\section{CONCLUSION}

In discussing the daily and occupational stressors above, it becomes apparent that statistical differences between the IBS and non-IBS group exist when comparing the two groups as a whole. When the IBS and control groups were divided into an older and younger group of women, and then compared on the DSI, no statistically significant differences were apparent between the two groups.

When considering the results of the OSI, however, a statistically significant difference was found between the older group of women suffering from IBS and their healthy counterparts. The IBS group in this instance showed significantly higher stress levels for minor stress that would typically be encountered in a work environment.

Establishing reasons for this phenomenon are beyond the scope of the current study, yet it is tantalising to contem- plate why the minor stressors measured by the OSI, which seem in many instances similar to those measured by the DSI, showed a marked difference among the older women with IBS in terms of stress measures by the OSI, but not the DSI.

Some hypotheses that may be explored here concern the effect that an accumulation of minor life stressors has on an individual's ability to cope with minor stressors at work and still perform effectively. Alternatively, the issue of younger women having a greater resilience to minor stress, particular in their occupational environment may be pertinent. A third possibility is that younger women may regard everyday hassles at work as challenges (coping with difficult relationships, braving traffic everyday, learning to deal with argumentative or rude individuals etc.), whereas older women may have become weary of the relentless nature of these stressors, and thus more susceptible to their effects.

The role of minor occupational stressors and the age split that becomes apparent in this study seems to be unique in the literature. Previous research regarding minor stressors and IBS have tended to concentrate on the issue of stress and its relationship to symptom exacerbation (Dancey et al. 1995:827; Suls et al. 1994:103). Clearly then, more research is needed to investigate the triad of IBS, minor occupational stressors and the effect that age may have on the relationships between the two issues.

These results have implications for the management of IBS patients and open the door for further research to explore the exact nature of the relationship between age, occupational stress and IBS. The research findings in this study appear to be unique, and as such they need to be replicated and verified before more in depth investigations be undertaken. Once again the tremendous scope of this field is highlighted, rich with new directions to explore and research opportunities to investigate that will bring us inexorably closer to understanding the enigma of irritable bowel syndrome.

\section{REFERENCES}

ARUN, P; KANWAL, K; VYAS, JN \& SUSHIL, CS 1993: Life events and irritable bowel syndrome. Indian Journal of Clinical Psychology, 20: 108 - 112.

BANDURA, A 1982: Self-efficacy mechanism in human agency. American Psychologist, 37: 122 - 147.

BENNET, P 1989: Irritable bowel syndrome. Nursing Times, 83(46), 51 - 53.

BLANCHARD, EB; SCHWARTZ, SP \& RADNITZ, CR 1987: Psychological assessment and treatment of irritable bowel syndrome. Behaviour modification, 11: $348-372$. BRANTLY, PH \& JONES, GN, 1989: The Daily Stress Inventory: Professional Manual. USA: Psychological Assessment Resources.

CAPLAN, G 1974: Support systems and community mental health. New York: Behavioural Publishing. 
CHAUDHARY, NA \& TRUELOVE, SC 1962: The irritable colon syndrome. Quarterly Journal of Medicine, 23: 307 - 322.

DANCEY, CP \& BACKHOUSE, S 1993: Towards a better understanding of patients with irritable bowel syndrome. Journal of Advanced Nursing, 18: $1443-1450$.

DANCEY, CP; WHITEHOUSE, A; PAINTER, J \& BACKHOUSE, S 1995: The relationship between hassles, uplifts and irritable bowel syndrome: a preliminary study. Journal of Psychosomatic Research, 39(7): 827 - 832.

DINAN, TG; O'KEANE, V; O'BOYLE, C; CHUA, A \& KEELING, PWN 1991: A comparison of the mental status, personality profiles and life events of patients with irritable bowel syndrome and peptic ulcer disease. Acta Psychiatrica Scandinavia, 84: $26-28$.

DROSSMAN, DA; MCKEE, DC; SANDLER, RS; MITCHELL, CM; CRAMER, EM; LOWMAN, BC \& BURGER, AL 1988: Psychosocial factors in the irritable bowel syndrome: a multivariate study of patients and nonpatients with irritable bowel syndrome. Gastroenterology, 95(3): $701-708$.

DROSSMAN, DA; SANDLER, RS; MCKEE, D \& LOWITZ, AJ 1982: Bowel patterns among subjects not seeking health care: use of a questionnaire to identify a population with bowel dysfunction. Gastroenterology, 70: $326-330$. ESLER, MD \& GOULSTON, KJ 1973: Levels of anxiety in colonic disorders. New England Journal of Medicine, 1973: $16-20$.

FAVA, GA \& PAVAN, L 1976/7: Large bowel disorders: lilness configuration and life events. Psychotherapy Psychosomatics, 27: 93 - 99.

GARDNER, RM; OSTROWSKI, TA; PINO, RD; MORRELL, JA \& KOCHEVAR, R 1992: Familiarity and anticipation of negative life events as moderator variables in predicting illness. Journal of Clinical Psychology, 48(5): 589 - 595. HISLOP, IG 1971: Psychological significance of the irritable colon syndrome. Gut, 12: 455 - 457.

HOLAHAN, CJ \& MOOS, RH 1985: Life stress and health: Personality, coping and family support in stress resistance. Journal of Personality and Social Psychology, 49(3): $739-747$.

HOLMES, TH \& RAHE, RH 1967: The Social Readjustment Rating Scale. Journal of Psychosomatic Research, 11: $213-218$.

KAPLAN, RM; SALLIS, JF \& PATTERSON, TL 1993: Health and Human Behaviour. New York: McGraw-Hill. KOBASA, SC 1979: Stressful life events: personality and health: An enquiry into hardiness. Journal of Personality and Social Psychology, 37: 1 - 11.

KOBASA, SC; MADDI, SR \& KAHN, S 1982: Hardiness and health: A prospective study. Journal of Personality and Social Psychology, 42: $168-177$.

KRANTZ, DS; GRUNBERG, NE \& BAUM, A 1985: Health Psychology. Annual review of Psychology, 36: 349 - 383. LANGELUDDECKE, PM 1985: Review: Psychological aspects of irritable bowel syndrome. Australian and New Zealand Journal of Psychiatry, 19: 218 - 226.

LATIMER, PR 1981: Irritable bowel syndrome: a behav- ioural model. Behaviour research and therapy, 19: 475 483.

LIN, N \& ENSEL, WM 1989: Life stress and health: stressors and resources. American Sociological Review, 54: 382 - 399.

MENDELOFF, AI; MONK, M; SIEGEL, CI \& LILIENFIELD, A 1970: liness experience and life stresses in patients with irritable colon and with ulcerative colitis. New England Journal of Medicine, 282(1): 14 - 17.

OSIPOW, H \& SPOKANE, JF 1987: The Occupational Stress Inventory: Professional Manual. USA: Psychological Assessment Resources.

RITCHIE, J 1973: Pain from distension of the pelvic colon by inflating a balloon in the irritable bowel syndrome. Gut, 14: 125 - , 132.

SANDLER, RS; DROSSMAN, DA; NATHAN, HP \& MCKEE, DC 1984: Symptom complaints and health care seeking behaviour in subjects with bowel dysfunction. Gastroenterology, 87: 314 - 318.

SCHUSTER, MM 1983: Irritable bowel syndrome. (In: Sleisenger, MH \& Fordtran, JS eds. 1983: Gastrointestinal disease: Pathophysiology, Diagnosis, Management; third edition. Volume 1. Philidelphia: WB Saunders.)

SMITH, EMJ 1985: Ethnic minorities: Life stress, social support and mental health issues. The Counselling Psychologist, 13(4): 537 - 579.

SNAPE, WJ; CARLSON, GM \& COHEN, S 1976: Colonic myoelectrical activity in the irritable bowel syndrome. Gut, 14: $125-132$.

SULS, J;WAN, CK \& BLANCHARD, EB 1994: A multilevel data analytic approach for evaluation of relationships between daily life stressors and symptomatology: Patients with irritable bowel syndrome. Health Psychology, 13(2): $103-113$.

WALKER, EA; ROY-BYRNE, PP; KATON, WJ; LI, L; AMOS, D \& JIRANEK, G 1990: Psychiatric illness and irritable bowel syndrome: A comparison with inflammatory bowel disease. American Journal of Psychiatry, 147(12): 1656 - 1661.

WHITEHEAD, WE; BOSMAJIAN, L; ZONDERMAN, AB; COSTA, PT \& SCHUSTER, MM 1988: Symptoms of psychologic distress associated with irritable bowel syndrome.

Gastroenterology, 95: $709-714$.

WHITEHEAD, WE; ENGEL, BT \& SCHUSTER, MM 1980: Irritable bowel syndrome: Physiological and psychological differences between diarrhoea-predominant and constipation-predominant patients. Digestive Diseases and Sciences, 25(6): $404-413$.

WHITEHEAD, WE; WINGET, C; FEDORAVICIUS, AS; WOOLEY, S \& BLACKWELL, B 1982: Learned illness behaviour in patients with irritable bowel syndrome and peptic ulcer. Digestive Diseases and Sciences, 27(3): $202-208$.

YOUNG, SJ; ALPERS, DH; NORL, CC \& WOODRUFF, RA 1976: Psychiatric illness and the irritable bowel syndrome: practical implications for the primary physician. Gastroenterology, 70: $162-166$. 